\title{
MODELS OF IMPROVING THE EFFICIENCY OF THE FUNCTIONING OF STATE INSTITUTIONS
}

\section{BobryakOV, A.; KLIMENKO, A.; BORISOV, V. \& TIKHONOVA, E.}

Abstract: The purpose of management in budget sectors of the economy is to optimize the performance of subordinate state institutions, which are a complicated, interconnected, integrated, territorial distributed complex, providing an effective solution of departmental tasks under conditions of limited resources for implementation. Actual management tasks which require profound information support and serious automation are sampling of objects with low values of performance indicators for the primary implementation of corrective actions, as well as a reasonable choice of the nomenclature of such corrective measures, taking into account the specific performance of a particular subordinate object. The article describes a generalized modeling procedure and presents a composite model for the formation of a well-grounded set of measures to improve the efficiency of the functioning of objects of complex organizational and economic systems. The composite model was developed using the sample of selecting activities aimed at increasing the efficiency of resource consumption of subordinate institutions and reducing the financial expenses for payment of energy resources.

Key words: budget sector of economy, fuzzy models.
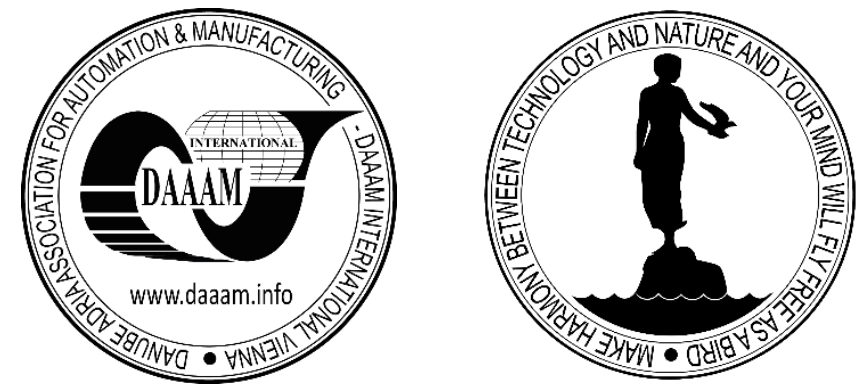

Authors' data: D.Sc. (Eng.) Head of Department Bobryakov, A[lexander]*; Univ.Prof. D.Sc. (Eng.) Klimenko, A[lexander]*; Univ.Prof. D.Sc. (Eng.) Borisov, V[adim]*; Dipl.-Ing. Tikhonova, E[lena ${ }^{*},{ }^{*}$ National Research University "Moscow Power Engineering Institute", Krasnokazarmennaya 14, Moscow, 111250, Russia, BobriakovAV@mpei.ru, TikhonovaYA@mpei.ru. KlimenkoAV@mpei.ru,_vbor67@mail.ru,

This Publication has to be referred as: Bobryakov, $\mathrm{A}[$ lexander]; Klimenko, A[lexander]; Borisov, V[adim] \& Tikhonova, E[lena] (2017). Models of Improving the Efficiency of the Functioning of State Institutions, Chapter 11 in DAAAM International Scientific Book 2017, pp.133-144, B. Katalinic (Ed.), Published by DAAAM International, ISBN 978-3-902734-12-9, ISSN 1726-9687, Vienna, Austria DOI: $10.2507 /$ daaam.scibook.2017.11 
Bobryakov, A.; Klimenko, A.; Borisov, V. \& Tikhonova, E.: Models of Improving t...

\section{Introduction}

The Management bodies and Subordinate Organizations and Institutions (SOI) of budget spheres of the Russian economy, in terms of their managerial processes, can be usually considered as Complex Organizational Economic Systems (COES). Elements of such systems are some organizational structures, which are legally formalized and linked hierarchically by vertical and horizontal links. The general aim of COES is to provide the public services, and carry out the productive and other socially significant functions. At the same time, the taking of system management decisions to optimize and improve the efficiency of the COES performance is implemented by the units of the upper levels of the system hierarchy. The made decisions are mandatory for execution by the lower (subordinate) units. Decision-making is based on information about the characteristics of the SOI performance, including indicators of the provision of public services (performance of works), as well as the financial and economic indicators of SOI. Information flows of indicators come from the lower hierarchical levels (the level of SOI) to the upper levels of the system (managerial level), where it is possible, after aggregation and processing, to evaluate how well the object performs. The primary statistical indicators and the generated statistical and analytic indicators form the so-called departmental information database for Supporting of Making Decisions (SMD) to control the COES. The software and technical platform of the information database of SMD are usually departmental Information and Analytic Systems (IAS) (Alashkevich et al., 2015).

The objective function of departmental institution is the provision of some specified public services (performance of works) which should meet the established quality standards, provided that the maximum performance effectiveness of spending budget funds is achieved. The achievement of the mentioned aim requires carrying out the work to optimize the functioning of the network of subordinate institutions, which are a complicated, interconnected, integrated, territorial distributed complex.

Optimization work is conducted with respect to every specific SOI with low performance indicators and, as a rule, involves the corrective measures for improving those low indicators. Due to the limited amount of departmental financial resources for such measures, within the framework of departmental management the following tasks required profound information support and serious automation should be solved:

- the formation of sampling of subordinate objects with low performance indicators, where the priority implementation of corrective actions is most appropriate;

- the formation of a well-grounded set of measures to improve the performance efficiency of every subordinate object, included into the sampling, due to the specific features of its functioning.

The aims to solve the first task are the following:

- targeted implementation with respect to selected objects (having low values of performance indicators) of certain organizational, economic or technical measures designed to eliminate deviations of the object's indicators from the optimal averaged or nominal values (elimination of "lagging" objects);

- detailed study of the objects chosen for the sampling and having high values of the performance indicators to form methodological recommendations for the other 
objects of COES when achieving the maximum values of the performance indicators (study of the best practices of the "best" objects).

Works (Bobryakov et al., 2016) consider in detail the solution of the task of formation of the described above sampling of subordinate objects. The solution is based on the implementation of the procedures of primary statistical processing of information arrays of indicators, calculation of the values of specific indicators used for evaluating the effectiveness of the functioning of objects, conducted by analyzing the departmental statistical distributions of the indicators studied.

Solution of the task of forming a set of well-grounded measures to increase the efficiency of the functioning of subordinate objects involves the development of a special model-methodical support, oriented to the regularities and peculiarities of each area of financial and economic activity.

The article describes the generalized modeling procedure and presents the compositional model for the formation of a well-grounded set of measures to improve the efficiency of some COES objects. The compositional model was developed using the samples of selecting activities aimed at increasing the efficiency of resource consumption of subordinate institutions and reducing the financial expenses for payment of energy resources. The compositional model includes: a model of a general assessment of the feasibility how to conduct a set of measures to improve the efficiency of resource consumption; models for assessing the feasibility how to conduct a set of measures to improve the efficiency of resource consumption of subsystems of power-, heat- and water supply; models for assessing the impact of measures on the performance of subsystems of power-, heat- and water supply.

\section{The formulation of the task how to form a set of measures to improve the efficiency of resource consumption of subordinate organizations and institutions and how to reduce financial costs for payment of energy resources.}

Let's consider a subordinate object $S$ for which the efficiency of the feasibility of implementing a set of measures to improve the efficiency of resource consumption is estimated by a general indicator $E(S)$.

The required set of measures is carried out on technical systems of resource supply of the object $S$ :

$$
S=\left\{s_{j}\right\}, j=1, \ldots, J .
$$

For the task being solved: $S=\left\{s_{1}, s_{2}, s_{3}\right\}$, where, $s_{1}, s_{2}, s_{3}$ - resource intensive subsystems of power supply, heat supply and water supply of SOI correspondingly.

Feasibility of implementing measures to increase the efficiency of resource consumption for these subsystems $s_{j}, j=1, \ldots, J$ is estimated by the corresponding indicators $e\left(s_{j}\right), j=1, \ldots, J$.

As a result, the feasibility of implementing a set of measures to increase the efficiency of resource consumption for the subordinate object is expressed by: 
Bobryakov, A.; Klimenko, A.; Borisov, V. \& Tikhonova, E.: Models of Improving t...

$$
E(S)=F\left(e\left(s_{1}\right), \ldots, e\left(s_{J}\right)\right) \text {. }
$$

In general, the indicators of feasibility of the conducting measures $e\left(s_{j}\right), j=1, \ldots, J$ for individual subsystems are characterized by different levels of consistency relative to the general estimation for the object.

The every subsystem of resource supply $s_{j} \in S$ is characterized by its own set of indicators:

$$
P\left(s_{j}\right)=\left\{p_{l}\left(s_{j}\right)\right\}, l=1, \ldots, L .
$$

For the task being solved:

$$
\forall s_{j}: P\left(s_{j}\right)=\left\{p_{1}\left(s_{j}\right), p_{2}\left(s_{j}\right), p_{3}\left(s_{j}\right), p_{4}\left(s_{j}\right), p_{5}\left(s_{j}\right)\right\}
$$

where

$p_{1}\left(s_{j}\right)$ - the indicator of technical condition of $j$ - subsystem;

$p_{2}\left(s_{j}\right)$ - the indicator characterizing the specifics of $j$ - subsystem;

$p_{3}\left(s_{j}\right)$ - the indicator of resource-saving potential of $j$-subsystem;

$p_{4}\left(s_{j}\right)$-share of $\mathrm{j}$-subsystem in the total volume of expenditures for the payment of resources of SOI;

$p_{5}\left(s_{j}\right)$ - tariffs for resource consumption of $j$ - subsystem.

For each subsystem $s_{j}, j=1, \ldots, J$ its own set of measures $A_{s_{j}}$ has been formed, aimed to increase the resource efficiency:

$$
A_{s_{j}}=\left\{a_{k_{j}}^{\left(s_{j}\right)}\right\}, k_{j}=1, \ldots, K_{j}
$$

In its turn, the set of measures $a_{k_{j}}^{\left(s_{j}\right)} \in A_{s_{j}}, k_{j}=1, \ldots, K_{j}$ has the following indicators:

$$
Q\left(a_{k_{j}}^{\left(s_{j}\right)}\right)=\left\{q_{m}\left(a_{k_{j}}^{\left(s_{j}\right)}\right)\right\}, m=1, \ldots, M .
$$

For the task being solved:

$$
\forall e_{k_{j}}^{\left(s_{j}\right)}: Q\left(a_{k_{j}}^{\left(s_{j}\right)}\right)=\left\{q_{1}\left(a_{k_{j}}^{\left(s_{j}\right)}\right), q_{2}\left(a_{k_{j}}^{\left(s_{j}\right)}\right), q_{3}\left(a_{k_{j}}^{\left(s_{j}\right)}\right)\right\},
$$

where,

$q_{1}\left(a_{k_{j}}^{\left(s_{j}\right)}\right)$ - the indicator characterizing the effect of the event $a_{k_{j}}^{\left(s_{j}\right)}$ on the technical state of $j$ - subsystem; 
$q_{2}\left(a_{k_{j}}^{\left(s_{j}\right)}\right)$ - the indicator characterizing the degree of correspondence of the event $a_{k_{j}}^{\left(s_{j}\right)}$ to the characteristics of $j$ - subsystem;

$q_{3}\left(a_{k_{j}}^{\left(s_{j}\right)}\right)$ - the indicator characterizing the impact of the event $a_{k_{j}}^{\left(s_{j}\right)}$ on the resourcesaving potential of $j$ - subsystem;

$q_{4}\left(a_{k_{j}}^{\left(s_{j}\right)}\right)$ - the indicator characterizing the cost of the event;

$q_{5}\left(a_{k_{j}}^{\left(s_{j}\right)}\right)$ - the indicator characterizing the terms of the event.

The formulation of the task is as follows. For the subordinate object $S$, which includes a set of resource-intensive subsystems $\left\{s_{1}, s_{2}, s_{3}\right\}$, it is required to form a set of measures $C(S)$ from the corresponding groups of their events $\left\{A_{s_{1}}, A_{s_{2}}, A_{s_{3}}\right\}$, and the feasibility of their implementation is characterized by the maximum value of the indicator $E(S)$, which will allow maximizing the efficiency of resource consumption of the object $S$.

A general indicator $E(S)$ is formed under the condition of a different level of consistency in the indicators of the feasibility of events for individual subsystems, as well as restrictions on the volume of financial expenditures $V(C(S))$ and the time $T(C(S))$ of conducting of the set of measures, that is:

$$
\begin{aligned}
& E(S) \stackrel{C(S)}{\longrightarrow} \max , \\
& V(C(S)) \leq V_{\max }(C(S)), \\
& T(C(S)) \leq T_{\max }(C(S)) .
\end{aligned}
$$

\section{Compositional model of the formation of a set of measures to improve the efficiency of the functioning of subordinate organizations and institutions}

\subsection{Structure of the compositional model to form a set of measures}

Figure 1 shows the structure of the compositional model for the formation of a set of measures to improve the efficiency of SOI performance, starting from the formulation of the research task made in the previous section.

The proposed compositional model includes the following ones:

- a model of a general assessment of the feasibility of implementing the measures for a subordinate object;

- a model of assessment of the feasibility of implementing the measures for subsystems: power supply; heat supply; water supply;

- a model of assessment of the measures' impact on the indicators of subsystems: power - , heat - and water supply.

Let's consider in detail the models listed above. 
Bobryakov, A.; Klimenko, A.; Borisov, V. \& Tikhonova, E.: Models of Improving t...

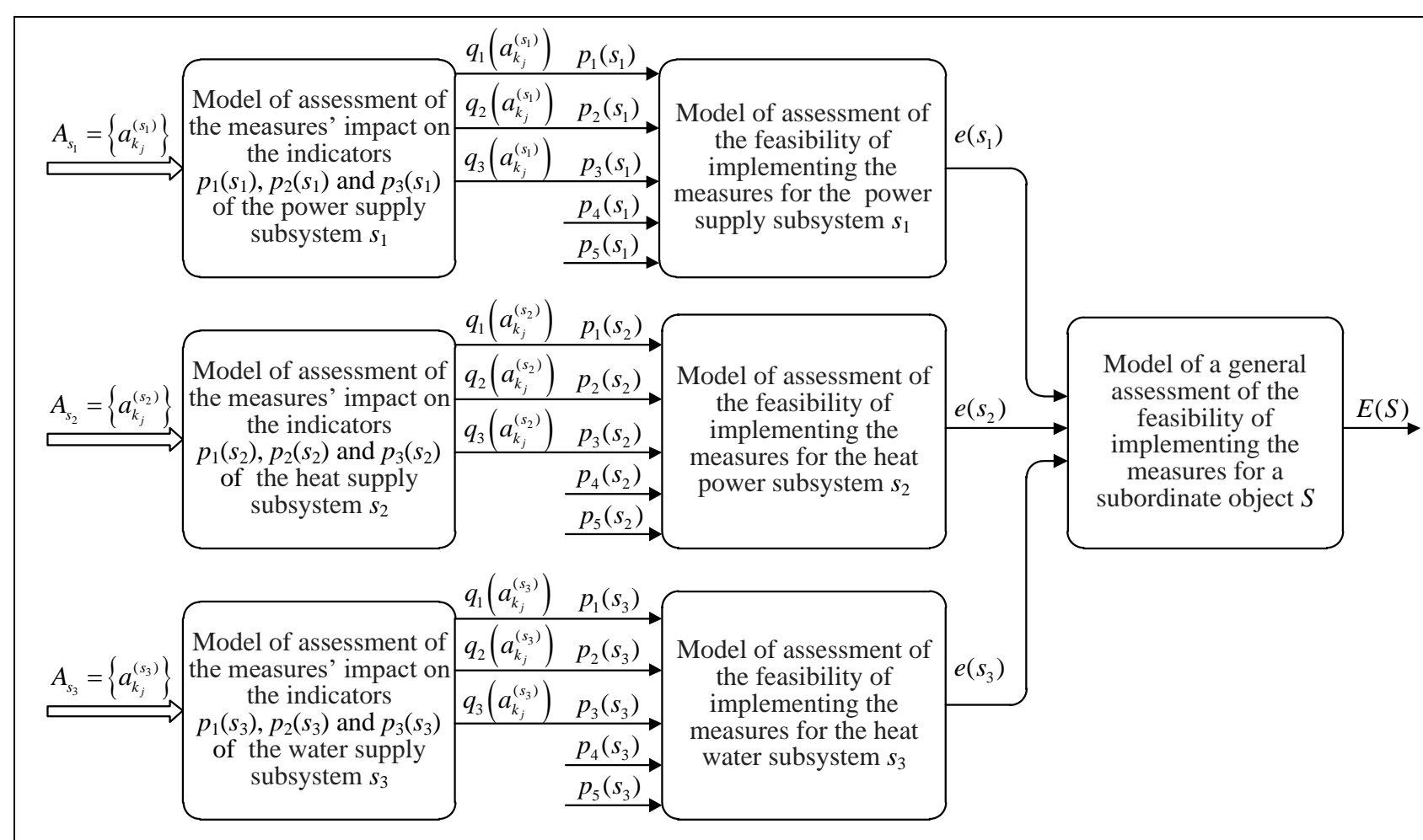

Fig. 1. Structure of the compositional model to arrange a set of measures for improving the efficiency of SOI performance

\subsection{The model of a general assessment of the feasibility of implementing the measures} for a subordinate object

Figure 2 presents an example of the structure of the model for a general assessment of implementing the measures for a subordinate object $S$, taking into account the levels of consistency of indicators $e\left(s_{1}\right), e\left(s_{2}\right)$ and $e\left(s_{3}\right)$ assessment of the feasibility of implementing measures to increase the efficiency of resource consumption of subsystems, such as power-, heat- and water supply, respectively.

Figure 2 shows the levels of consistency (compatibility) $\operatorname{con}_{s_{j}, s_{g}}(j, g=1, \ldots, J)$ between the indicators $e\left(s_{j}\right)(j=1, \ldots, J)$ of subsystems: power-, heat- and water supply. Moreover:

$$
\operatorname{con}_{s_{j}, s_{g}} \in\{N C, L C, M C, H C, F C\}, \quad j, g=1, \ldots, J,
$$

where,

$N C$ - low level of compatibility,

$L C$ - compatibility level below average,

$M C$ - average level of compatibility,

$H C$ - compatibility level above average,

$F C$ - high level of compatibility. 


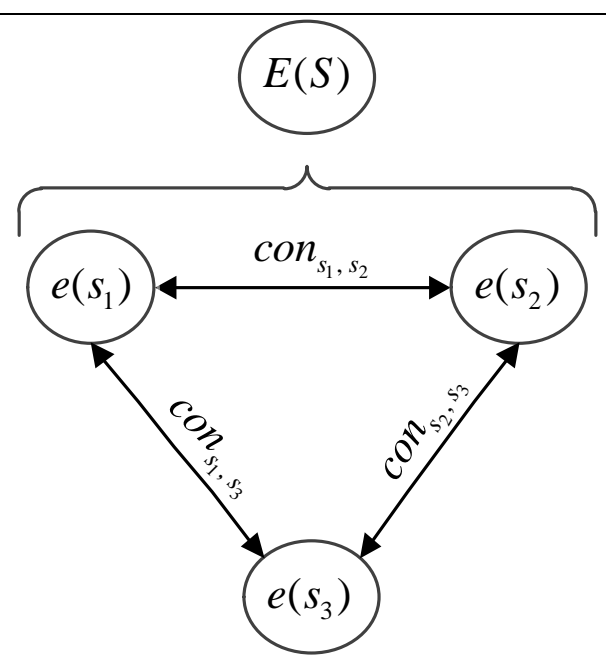

Fig. 2. Structure of the model of a general assessment of the feasibility of implementing the measures for a subordinate object

To determine these levels of consistency, different approaches can be used, for example, considering $\operatorname{con}_{s_{j}, s_{g}}(j, g=1, \ldots, J)$ from the point of view of their correlation or mutual influence and defining them both analytically and expertly (Andreev \& Borisov, 2015).

As an example, we define the following levels of consistency:

$\operatorname{con}_{s_{1}, s_{2}}=M C ; \operatorname{con}_{s_{1}, s_{3}}=L C ; \operatorname{con}_{s_{2}, s_{3}}=H C$.

The levels of consistency between the indicators $e\left(s_{1}\right), e\left(s_{2}\right)$ and $e\left(s_{3}\right)$ of power-, heatand water supply subsystems are used to compare the convolution operations of these indicators.

Table 1 compares the levels of consistency of indicators with the operations of their convolution.

\begin{tabular}{|c|c|c|}
\hline № & Levels of consistency of indicators & Conversion operations $e\left(s_{j}\right)$ и $e\left(s_{g}\right)$ \\
\hline 1 & $N C$ & $\min \left(e\left(s_{j}\right), e\left(s_{g}\right)\right)$ \\
\hline 2 & $L C$ & $\operatorname{med}\left(e\left(s_{j}\right), e\left(s_{g}\right) ; 0,25\right)$ \\
\hline 3 & $M C$ & $\operatorname{med}\left(e\left(s_{j}\right), e\left(s_{g}\right) ; 0,5\right)$ \\
\hline 4 & $H C$ & $\operatorname{med}\left(e\left(s_{j}\right), e\left(s_{g}\right) ; 0,75\right)$ \\
\hline 5 & $F C$ & $\left.\max \left(e\left(s_{j}\right), e\left(s_{g}\right)\right)\right)$ \\
\hline
\end{tabular}

Tab. 1. Comparison of the compatibility levels of indicators with convolution operations

To obtain a general assessment of the feasibility of implementing a set of measures for a subordinate object using this model, one of the following assessment strategies must be set, determining, first of all, the order of viewing the compatibility levels of the indicators when choosing the order of their aggregation using the corresponding convolution operations, and then revision of the compatibility levels after each operation of convolution indicators: 
Bobryakov, A.; Klimenko, A.; Borisov, V. \& Tikhonova, E.: Models of Improving t...

- from the most to the least consistent indicators;

- from the least to the most consistent indicators.

This article presents an assessment strategy from the most to the least consistent indicators.

As a result, the following model of the general assessment of the feasibility of implementing a set of measures for the subordinate object was formed:

$$
E(S)=\operatorname{med}\left(e\left(s_{1}\right), \operatorname{med}\left(e\left(s_{2}\right), e\left(s_{3}\right) ; 0,75\right) ; 0,25\right) .
$$

3.3. The models for assessing the feasibility of implementing measures for power-, heat- and water supply subsystems

Due to the necessity to take into account the uncertainty in assessing the impact of various factors on the feasibility of implementing measures for the subsystems of power-, heat- and water supply, we will use an indistinct-logical approach as the basis for the models being created. This approach allows us to typify the representation of input, output indicators and constraints in the form of fuzzy statements in the prerequisites and conclusions of production rules, and for the assessment itself to use the methods of fuzzy inference (Zimmermann H.-J., 2001).

We consider the procedures for constructing and using the proposed models using the example of the feasibility assessment model for the implementation of measures for the power supply subsystem. The procedure for constructing this model includes the following steps.

Stage 1. Setting the structure of the fuzzy production model for assessing the resource efficiency of the power supply subsystem. This model has the following fuzzy input variables:

- $p_{1}\left(s_{1}\right)$ - state of subsystem ${ }^{s_{1}}$;

- $p_{2}\left(s_{1}\right)$ - specifics of the subsystem $s_{1}$;

- $p_{3}\left(s_{1}\right)_{-}$resource potential of the subsystem $s_{1}$;

- $p_{4}\left(s_{1}\right)_{-}$share of the subsystem $s_{1}$ in the total expenditures for resources;

- $p_{5}\left(s_{1}\right)_{-}$tariffs for resource consumption of the subsystem $s_{1}$.

Wherein the values of the indicators $p_{1}\left(s_{1}\right), p_{2}\left(s_{1}\right)$ and $p_{3}\left(s_{1}\right)$ come to the inputs of this model from the outputs of the model of the effect of measures on the indicators of the subsystem of power supply, and the values of the indicators $p_{4}\left(s_{1}\right)$ and $p_{5}\left(s_{1}\right)$ come directly to this model (see Figure 1). The output of the fuzzy variable is the indicator $e\left(s_{1}\right)$ of the feasibility of implementing measures for the power supply subsystem.

Stage 2. The construction of Linguistic Scales for input and output fuzzy variables.

We use triangular membership functions for fuzzy sets (Babuška, 2012). Wherein the number of terms for describing all variables is given by the same ones $\{L-$ small, $M$ - medium, $H$-large $\}$. For the model under consideration: 


$$
\begin{aligned}
& p_{1}\left(s_{1}\right):\left\{L_{p_{1}\left(s_{1}\right)}, M_{p_{1}\left(s_{1}\right)}, H_{p_{1}\left(s_{1}\right)}\right\} ; p_{2}\left(s_{1}\right):\left\{L_{p_{2}\left(s_{1}\right)}, M_{p_{2}\left(s_{1}\right)}, H_{p_{2}\left(s_{1}\right)}\right\} ; \\
& p_{3}\left(s_{1}\right):\left\{L_{p_{3}\left(s_{1}\right)}, M_{p_{3}\left(s_{1}\right)}, H_{p_{3}\left(s_{1}\right)}\right\} ; p_{4}\left(s_{1}\right):\left\{L_{p_{4}\left(s_{1}\right)}, M_{p_{4}\left(s_{1}\right)}, H_{p_{4}\left(s_{1}\right)}\right\} ; \\
& p_{5}\left(s_{1}\right):\left\{L_{p_{5}\left(s_{1}\right)}, M_{p_{5}\left(s_{1}\right)}, H_{p_{5}\left(s_{1}\right)}\right\} ; e\left(s_{1}\right):\left\{L_{e\left(s_{1}\right)}, M_{e\left(s_{1}\right)}, H_{e\left(s_{1}\right)}\right\} .
\end{aligned}
$$

Stage 3. Creation of the base of fuzzy production rules of the model of the following type:

Rule 1 : If $p_{1}\left(s_{1}\right)$ is $L_{p_{1}\left(s_{1}\right)}$ And $p_{2}\left(s_{1}\right)$ is $L_{p_{2}\left(s_{1}\right)}$ And $p_{3}\left(s_{1}\right)$ is $L_{p_{3}\left(s_{1}\right)}$ And $p_{4}\left(s_{1}\right)$ is $L_{p_{4}\left(s_{1}\right)}$ And $p_{5}\left(s_{1}\right)$ is $L_{p_{5}\left(s_{1}\right)}$, Then $e\left(s_{1}\right)$ is $L_{e\left(s_{1}\right)}$;

Rule $_{y}$ : If $p_{1}\left(s_{1}\right)$ is $M_{p_{1}\left(s_{1}\right)}$ And $p_{2}\left(s_{1}\right)$ is $M_{p_{2}\left(s_{1}\right)}$ And $p_{3}\left(s_{1}\right)$ is $M_{p_{3}\left(s_{1}\right)}$ And $p_{4}\left(s_{1}\right)$ is $M_{p_{4}\left(s_{1}\right)}$ And $p_{5}\left(s_{1}\right)$ is $M_{p_{5}\left(s_{1}\right)}$, Then $e\left(s_{1}\right)$ is $M_{e\left(s_{1}\right)}$;

Rule $_{Y}$ : If $p_{1}\left(s_{1}\right)$ is $H_{p_{1}\left(s_{1}\right)}$ And $p_{2}\left(s_{1}\right)$ is $H_{p_{2}\left(s_{1}\right)}$ And $p_{3}\left(s_{1}\right)$ is $H_{p_{3}\left(s_{1}\right)}$ And $p_{4}\left(s_{1}\right)$ is $H_{p_{4}\left(s_{1}\right)}$ And $p_{5}\left(s_{1}\right)$ is $H_{p_{5}\left(s_{1}\right)}$, Then $e\left(s_{1}\right)$ is $H_{e\left(s_{1}\right)}$.

The procedure for using the constructed fuzzy production model for assessing the feasibility of implementing measures for the power supply subsystem consists of the following stages.

Stage 1. Determination of the degree of belonging of values of input variables for all fuzzy statements in the prerequisites of all rules.

For the Rule ${ }_{1}$ from the base of rules: determination of the degree of belonging $\mu_{L_{p_{1}\left(s_{1}\right)}}\left(p_{1}^{\prime}\left(s_{1}\right)\right), \mu_{L_{p_{2}\left(s_{1}\right)}}\left(p_{2}^{\prime}\left(s_{1}\right)\right), \mu_{L_{p_{3}\left(s_{1}\right)}}\left(p_{3}^{\prime}\left(s_{1}\right)\right), \mu_{L_{p_{4}\left(s_{1}\right)}}\left(p_{4}^{\prime}\left(s_{1}\right)\right)$ and $\mu_{L_{p_{5}\left(s_{1}\right)}}\left(p_{5}^{\prime}\left(s_{1}\right)\right)$ fuzzy sets $L_{p_{1}\left(s_{1}\right)}, L_{p_{2}\left(s_{1}\right)}, L_{p_{3}\left(s_{1}\right)}, L_{p_{4}\left(s_{1}\right)}$ and $L_{p_{5}\left(s_{1}\right)}$ by values $p_{1}^{\prime}\left(s_{1}\right), p_{2}^{\prime}\left(s_{1}\right), p_{3}^{\prime}\left(s_{1}\right)$, $p_{4}^{\prime}\left(s_{1}\right)$ and $p_{5}^{\prime}\left(s_{1}\right)$, respectively.

Similarly, the degree of belonging to the values of the input variables for all statements in the prerequisites of all other rules are found.

Stage 2. Aggregation of the degrees of truth of fuzzy statements of assumptions for each rule:

$$
\begin{aligned}
& \alpha_{1}=\min \left(\mu_{L_{p_{1}\left(s_{1}\right)}}\left(p_{1}^{\prime}\left(s_{1}\right)\right), \mu_{L_{p_{2}\left(s_{1}\right)}}\left(p_{2}^{\prime}\left(s_{1}\right)\right), \mu_{L_{p_{3}\left(s_{1}\right)}}\left(p_{3}^{\prime}\left(s_{1}\right)\right), \mu_{L_{p_{4}\left(s_{1}\right)}}\left(p_{4}^{\prime}\left(s_{1}\right)\right), \mu_{L_{p_{5}\left(s_{1}\right)}}\left(p_{5}^{\prime}\left(s_{1}\right)\right)\right), \\
& \ldots \\
& \alpha_{y}=\min \left(\mu_{M_{p_{1}\left(s_{1}\right)}}\left(p_{1}^{\prime}\left(s_{1}\right)\right), \mu_{M_{p_{2}\left(s_{1}\right)}}\left(p_{2}^{\prime}\left(s_{1}\right)\right), \mu_{M_{p_{3}\left(s_{1}\right)}}\left(p_{3}^{\prime}\left(s_{1}\right)\right), \mu_{M_{p_{4}\left(s_{1}\right)}}\left(p_{4}^{\prime}\left(s_{1}\right)\right), \mu_{M_{p_{5}\left(s_{1}\right)}}\left(p_{5}^{\prime}\left(s_{1}\right)\right)\right), \\
& \ldots \\
& \alpha_{Y}=\min \left(\mu_{H_{p_{1}\left(s_{1}\right)}}\left(p_{1}^{\prime}\left(s_{1}\right)\right), \mu_{H_{p_{2}\left(s_{1}\right)}}\left(p_{2}^{\prime}\left(s_{1}\right)\right), \mu_{H_{p_{3}\left(s_{1}\right)}}\left(p_{3}^{\prime}\left(s_{1}\right)\right), \mu_{\left.H_{p_{4}\left(s_{1}\right)}\right)}\left(p_{4}^{\prime}\left(s_{1}\right)\right), \mu_{H_{p_{5}\left(s_{1}\right)}}\left(p_{5}^{\prime}\left(s_{1}\right)\right)\right) .
\end{aligned}
$$

Stage 3. Activating the conclusions for each rule: 
Bobryakov, A.; Klimenko, A.; Borisov, V. \& Tikhonova, E.: Models of Improving t...

$$
\begin{aligned}
& \mu_{L_{e\left(s_{1}\right)}^{\prime}}\left(e\left(s_{1}\right)\right)=\min \left(\alpha_{1}, \mu_{L_{e\left(s_{1}\right)}}\left(e\left(s_{1}\right)\right)\right), \\
& \mu_{M_{e\left(s_{1}\right)}^{\prime}}\left(e\left(s_{1}\right)\right)=\min \left(\alpha_{y}, \mu_{M_{e\left(s_{1}\right)}}\left(e\left(s_{1}\right)\right)\right), \\
& \mu_{H_{e\left(s_{1}\right)}^{\prime}}\left(e\left(s_{1}\right)\right)=\min \left(\alpha_{y}, \mu_{H_{e\left(s_{1}\right)}}\left(e\left(s_{1}\right)\right)\right) .
\end{aligned}
$$

Stage 4. Accumulation of activated conclusions of the rules:

$$
\mu_{e^{\prime}\left(s_{1}\right)}\left(e\left(s_{1}\right)\right)=\max \left(\mu_{L_{e\left(s_{1}\right)}^{\prime}}\left(e\left(s_{1}\right)\right), \ldots, \mu_{M_{e\left(s_{1}\right)}^{\prime}}\left(e\left(s_{1}\right)\right), \ldots, \mu_{H_{e\left(s_{1}\right)}^{\prime}}\left(e\left(s_{1}\right)\right)\right) .
$$

Stage 5. Obtaining clear values for the output variable:

$$
e^{\prime}\left(s_{1}\right)=\frac{\sum_{n=1}^{N} e\left(s_{1}\right)_{(n)} \cdot \mu_{e^{\prime}\left(s_{1}\right)}\left(e\left(s_{1}\right)_{(n)}\right)}{\mu_{e^{\prime}\left(s_{1}\right)}\left(e\left(s_{1}\right)_{(n)}\right)},
$$

where $K$ - the number of elements in the sampling base set of the output variable $e\left(s_{1}\right)$.

Note. Similarly, construction and use of fuzzy production models for assessing the feasibility of implementing measures for the subsystems of heat and water supply.

3.4. Models for assessing the impact of measures on the performance of subsystems of power-, heat- and water supply

The input variables of each of these models are measures $a_{k_{j}}^{\left(s_{j}\right)} \in A_{s_{j}}, k_{j}=1, \ldots, K_{j}$ from the groups of events corresponding to a particular subsystem $s_{j}, j=1, \ldots, J$; but output variables $q_{1}\left(a_{k_{j}}^{\left(s_{j}\right)}\right)$ - an indicator characterizing the impact of the measure $a_{k_{j}}^{\left(s_{j}\right)}$ on the technical state of the $j$ - subsystem; $q_{2}\left(a_{k_{j}}^{\left(s_{j}\right)}\right)$ - an indicator characterizing the degree of correspondence of an measure $a_{k_{j}}^{\left(s_{j}\right)}$ to the characteristics of the $j$ - subsystem; $q_{3}\left(a_{k_{j}}^{\left(s_{j}\right)}\right)$ - an indicator characterizing the impact of the event $a_{k_{j}}^{\left(s_{j}\right)}$ on the change in the resource-saving potential of the $j$ - subsystem.

A different set of factors and the nonlinear character of the dependencies between them allows justifying the use of fuzzy cognitive maps for constructing these models (Kosko B., 1986; Stylios, 2004). An example of a developed fuzzy cognitive map for assessing the impact of measures on the indicators of the power supply subsystem is given in (Borisov et al., 2016). 
3.5. Modeling for the formation of a set of measures to improve the performance of subordinate organizations and institutions

The modeling procedure for the formation of a set $C(S)$ of measures to improve the efficiency of the functioning of subordinate organizations and institutions using the developed compositional model in a general form consists in assigning various combinations of measures $a_{k_{j}}^{\left(s_{j}\right)} \in A_{s_{j}}, k_{j}=1, \ldots, K_{j}$ for all resource-intensive subsystems $\left\{s_{1}, s_{2}, s_{3}\right\}$ when the restrictions on the volume of financial expenditures and the time of their implementation are established, and in defining such a set of the measures, which provides the maximum value of the general indicator $E(S)$.

\section{Conclusion}

The article describes a possible problem solution how to increase the efficiency of the functioning of the subordinate organizations and institutions of the budget spheres of the Russian economy.

The article proposes an original formulation of the research task, which consists in setting up measures to improve the efficiency of resource consumption of subordinate organizations and institutions and to reduce financial expenditures for the payment of energy resources, subject to restrictions on the amount of financial costs and the time of implementation of these measures.

To solve this problem, the authors propose a new approach based on the created composite model for setting up measures to improve the efficiency of the functioning of subordinate organizations and institutions. The proposed composite model includes a set of the following developed models:

- a model for a generalized assessment of the feasibility of implementing a set of measures for a subordinate facility that allows considering different consistency and significance of the assessment indicators for individual subsystems of this object;

- fuzzy logic models for assessing the feasibility of implementing measures for subsystems of electricity, heat and water supply;

- assessment models of the impact of activities on the indicators of subsystems of electricity, heat and water supply which are based on fuzzy cognitive maps.

The article describes a general modeling procedure for forming a set of measures to improve the efficiency of resource consumption of subordinate organizations and institutions and to reduce financial costs for the payment of energy.

The proposed approach based on composite model has been successfully tested on the arrays of statistical data on the consumption of energy resources by institutions and organizations subordinate to the Ministry of Education and Science of the Russian Federation in the performance of a number of state research projects carried out by the National Research University "Moscow Power Engineering Institute".

A further line of research is the creation of intellectual information technology to form a set of measures to improve the efficiency of the functioning of organizations and institutions subordinate to the Ministry of Education and Science of Russia and 
Bobryakov, A.; Klimenko, A.; Borisov, V. \& Tikhonova, E.: Models of Improving t... can be used to solve tasks of departmental management in other Ministries and departments of the budgetary sector of the economy.

\section{Acknowledgements}

The authors are grateful to:

- Employees of the Department of Finance, the organization of the budgetary process, methodology and economics of education and science of the Ministry of Education and Science of Russia for providing methodological assistance in setting and solving the described task, as well as providing data for approbation of models;

- Employees of the Center for Industry Information and Analytical Systems of the National Research University "Moscow Power Engineering Institute" for methodical and expert assistance in the development of elements of the proposed models.

The reported study was funded by Russian Science Foundation, according to the research project № 16-19-10568.

\section{References}

Alashkevich, M; Bobryakov, A.; Klimenko, A.; Stefantsov, A. (2015). Automation and Informational Support of Budgetary Institution Financing Processes. Chapter 27 in DAAAM International Scientific Book 2015, pp. 319-328, B. Katalinic (Ed), Published by DAAAM International, ISBN 978-3-902734-05-1, ISSN 1726-9687, Vienna, Austria. DOI: 10.2507/daaam.scibook.2015.27.

Andreev S.N., Borisov V.V. (2015) Linguistic Analysis Based on Fuzzy Similarity models. In "Sequences in Language and Text". Iss. 69. P. 7-34./ Edited by G.K. Mikros, J. Macutek. Berlin/Boston: De Gruyter Mouton. ISBN 978-3-11-036273-2.

Babuška R. (2012) Fuzzy modeling for control. Springer Science \& Business Media, ISBN 978-94-010-6040-0. 2012, 260 p.

Bobryakov A.; Kozliuk D.; Rybakov D. (2016). An Approach to the Organization of Preliminary Data Processing in Information Arrays of the Characteristics of Object Functioning in Complex Organizational System. ISSN 1313-9126. In 26th National scientific symposium «Metrology And Metrology Assurance 2016». September 7-11, 2016, Sozopol, Bulgaria, PP. 361-366.

Borisov V., Stefantsov A., Gasho E., Postelnik M., Bobryakov A. (2016) Research into the Sustainable Development Problem of Urban Electric Power Systems on the Basis of Cognitive Modeling Technology // International Journal of Applied Engineering Research. ISSN 0973-4562, 2016. Vol. 11, No 24, PP. 11826-11831.

Kosko B. (1986). Fuzzy Cognitive Maps. International Journal of Man-Machine Studies. Vol. 24, 1986, PP. 65-75.

Stylios C. (2004) Modeling Complex Systems Using Fuzzy Cognitive Maps. IEEE Transactions on Systems, Man and Cybernetics. ISSN 0018-9472. Vol. 34, 2004, PP. $155-162$.

Zimmermann H.-J. (2001) Fuzzy Set Theory and Its Applications. Springer, 4th ed, ISBN 0792374355, 2001. $407 \mathrm{p}$. 